\title{
The Potential of Mimosa pudica as a Biopreservative for Food Products: a Bio processing Perspective
}

\author{
Fadzlie Wong Faizal Wong ${ }^{1,2 *}$, Mohd Ezuan Khayat ${ }^{2,3}$, Zulfazli M Sobri ${ }^{1,2}$ and Arbakariya B Ariff ${ }^{1,2}$ \\ ${ }^{1}$ Faculty of Biotechnology and Biomolecular Sciences, Universiti Putra Malaysia, Malaysia \\ ${ }^{2}$ Faculty of Biotechnology and Biomolecular Sciences, Bioprocessing and Biomanufacturing Research Centre, Universiti Putra Malaysia, Malaysia \\ ${ }^{3}$ Faculty of Biotechnology and Biomolecular Sciences, Universiti Putra Malaysia, Malaysia
}

Submission: December 01, 2017; Published: February 19, 2018

*Corresponding author: Fadzlie Wong Faizal Wong, Department of Bioprocess Technology, Faculty of Biotechnology and Biomolecular Sciences, Universiti Putra Malaysia, 43400 UPM Serdang, Selangor, Malaysia, Tel: +603-8946 1297; Email: fadzlie@upm.edu.my

\begin{abstract}
The plant extracts from various parts of Mimosa pudica exhibits significant antimicrobial activities against a wide range of food borne pathogens. The presence of active constituents can be manipulated for the biopreservative application in food industry. Biotechnological approach for the production of the antimicrobial compounds from M. pudica can be achieved via cell suspension culture and hairy root culture. The bioprocessing aspects of the two systems are similar to microbial biotechnology, except the bioreactor design required. In addition, the downstream processing of the two cell culture systems is also easier compared to the conventional whole plant extraction, as metabolites secretion can be achieved using exudation technique. The selection of solvent during the extraction should be made in regard to the stability of compounds and food safety. This mini review presents an up-to-date picture on the potential use of natural antimicrobial derived from $M$. pudica from a bioprocessing point of view that could be the key to successful production of plant-based biopreservative in food industry.
\end{abstract}

Keywords : Mimosa pudica; Biopreservative; Antimicrobial; Food; Bioprocessing

Abbreviations : DCM: Dichloromethane; GMP: Good Manufacturing Practice; PAP: Plant Antimicrobial Peptide;

\section{Introduction}

The discovery of natural antimicrobials is consistent with the growing demand due to consumer awareness of natural food products and the concern of microbial resistance towards conventional food processing and preservation methods. Generally, bio-preservative can be made from antimicrobial metabolites (e.g., bacteriocin, other metabolites, plant extracts, and enzymes), fermentates, cultures, and bacteriophages [1]. Interestingly, bio-preservative should be used in combination rather than in isolation, as well as together with a physical process like thermal processing to improve its efficacy [2]. Biopreservation allows shelf life of food products to be extended using natural origin. In order to prevent the growth of spoilage microorganisms in foods, the antimicrobials can be applied directly into the food formulation, coated on its surface, or incorporated into packaging materials [3].

To date, the use and production of bacteriocin for biopreservation has been widely reported in the literature $[2,4,5]$. However, report on the bio-processing aspects for plant cellbased compound s remains scarce. Mimosa pudica, or also known as sensitive plant, shy plant or touch-me-not is a pantropical weed that can be found in Asian countries including Malaysia. This creeping annual plant belongs to the family of Fabaceae and mostly recognized by its rapid movement in response to touch or vibration. This sensitivity is termed as seismonatic, where the leaves closed upon stimulation and reopen within minutes [6]. M. pudica is mainly used in folk medicine to treat diseases such as diabetes, obesity, urinary infection, hepatitis, and cancers due to the abundance in valuable secondary metabolites [7]. In addition to its pharmacological benefits, there is emerging evidence that $M$. pudica also has a huge potential to be used as a biopreservative for food products. M. pudica is a generous source to supply man with valuable bioactive substances. Phytochemicals analysis revealed that the antimicrobial activities of M. pudica are due to the presence of active constituents like alkaloids (i.e., basic-forming water-soluble salt, which also soluble in water, ethanol, ethyl acetate, and diethyl ether), flavonoids (i.e., phenolic structure found in photosynthesising cell and can be found in aqueous extract), essential oil/terpene (i.e., a naturally-occurring hydrocarbon based on combinations of isoprene unit, high in ethanol, methanol, and dichloromethane, but not in aqueous, 
and hexane extracts), quinones (i.e., compound with aromatic rings with two ketones substitution), resins (i.e., non-volatile compounds, e.g., glycosides and saponins; they are waterinsoluble but are soluble in organic solvent like ethanol), and tannins and coumarin (i.e., phenolic substances found in all parts; found in higher concentration in ethanol extract than aqueous extract), as well as chlorophyllin (water-soluble salt) [8-11]. In this mini review, the potential of $M$. pudica as a source of biopreservative in food products and its biotechnological production will be discussed.

\section{Antimicrobial Properties of M. pudica Extract}

Extracts from different parts of $M$. pudica have been shown to possess antibacterial activity. The extracts of Mimosa pudica leaves showed inhibitory effects against gram-positive bacteria such as $S$. aureus, $K$. pneumoniae, $B$. cereus, and $B$. subtilis as well as gram-negative bacteria such as E. coli, S.typhi, P. aeruginosa, and P. vulgaris $[12,13]$. The minimum inhibitory concentrations for methanol extract of M. pudica leaves against $S$. aureus, B. subtilis, K. pneumoniae, $P$. vulgaris and $P$. aeruginosa are ranging from $0.44-0.88 \mathrm{mg} / \mathrm{ml}$ [12]. The content of bioactive compounds in $M$. pudica leaves extracts might differ depending on extraction methods used. The ethanol extract of $M$. pudica leaves, which contains about three-fold higher flavonoids content than aqueous extract, showed greater inhibitory effects on four different bacteria compared to aqueous extract, suggesting flavonoids are among responsible compounds for the antibacterial activity [13]. Furthermore, the extracted chlorophyllin from the leaves of $M$. pudica also showed an inhibitory effect towards grampositive and gram-negative bacteria, indicating that this compound also plays a role in antibacterial activity [11]. The dichloromethane (DCM) and methanol extracts of $M$. pudica stems are able to inhibit $S$. aureus, B. cereus, B. subtilis E. coli, and P. aeruginosa [14]. The minimum inhibitory concentrations for these bacteria are ranging from $0.625-2.50 \mathrm{mg} / \mathrm{ml}$ [14]. These extracts also showed no significant toxicity towards brine shrimps, suggesting their activities are specific only to bacteria [14]. The ethyl acetate and methanol extracts of $M$. pudica roots have been shown to inhibit gram-positive bacteria such as $S$. epidermidis, $S$. aureus, S. pneumoniae, and B. subtilis as well as gram-negative bacteria such as S. typhi, E. coli, P. aeruginosa, P. vulgaris, and N. cinerea [15]. The minimum inhibitory concentrations of the root extracts towards the bacteria are ranging from $0.39-50 \mathrm{mg} / \mathrm{ml}$ [15]. In addition, the petroleum ether extract of $M$. pudica roots majorly contained flavonoids, phytosterol, alkaloids, and amino acids. On the other hand, the acetone and chloroform extracts showed the presence of flavonoids and alkaloids, respectively [9]. By using NMR, Panda et al. [15] have identified two new compounds in the methanol extract of $M$. pudica root that have the minimum inhibitory concentration in $\mu \mathrm{g} / \mathrm{ml}$ range against various bacteria.

\section{General Antimicrobial Mechanism of Actions}

Alkaloids are involved in the attenuation of bacterial pathogenicity by interfering with the virulence gene regulatory systems such as quorum sensing [16]. Tannins have been found to form irreversible complexes with highly rich protein resulting in the inhibition of cellular protein synthesis [17]. Flavonoids have antifungal activity by inhibiting spore germination of pathogens [18]. Saponins are detergent-like substances thus increases cell permeability of bacterial cell membrane, causing subsequent leakage of ions, ATP, nucleic acids, and amino acids [19]. Terpenoids also act by damaging the cytoplasmic membrane of bacterial cells through its hydrophobic nature [20]. Phenolic groups can cause severe structural damage and significant morphological alteration by damaging the integrity of bacterial cell wall [21].

\section{Biotechnological Approach for Production}

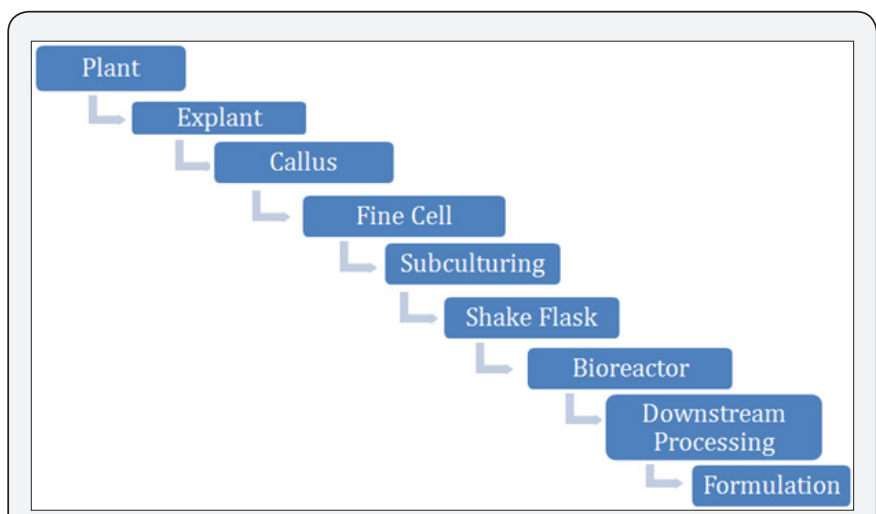

Figure 1: The overall production scheme of the antimicrobial compounds from M. pudica based on cell suspension culture.

Biotechnological approach is seen as the alternative to the conventional route for the production of antimicrobial compounds (i.e., extraction from the original plant source), owing to its high productivity. Besides, in the conventional route, the antimicrobial activity is affected by many factors: botanical source, time of harvesting, stage of development, and method of extraction [22]. Two established technologies, i.e., cell suspension culture (Figure 1) and hairy root culture are usually employed. Prior to bioreactor system, the development of callus tissue culture is required in the former system while a submerged hairy root culture is needed in the latter. Then, the bio-processing for the two systems is similar except that different bioreactor designs are required. The crucial step in the production scheme starts during the sub culturing stage. Here, highly productive cell lines are selected and the yield is improved through addition of elicitors (e.g., vanadyl sulphate and methyl jasmonate), medium optimisation, and "omics" approaches [23]. From the shake flask system, it was then transferred to bioreactor, where many selections design are available, e.g., airlift and bubble column bioreactor, not to mention, new design like centrifugal impeller bioreactor, wave, wave and undertow bioreactor, and mist (for hairy root system) 
bioreactors. In addition, disposable bioreactor can also be used to provide faster turnaround time as cleaning, assembling, and autoclaving operations are eliminated. Also, water use and validation requirements are minimized. Moreover, during bioreactor operation, optimization of operating conditions (e.g., temperature, aeration, and agitation) and the use of fedbatch, and perfusion mode operation can be considered to improve yield (Figure 1).

\section{Downstream Processing}

In conventional production (i.e., using the whole plant), the downstream processing usually involves mechanical disruption method like homogenization, sonication, or steam explosion or the advance technique like vacuum infiltrationcentrifugation, rhizosecretion, and guttation [24,25] prior to solvent extraction. Nevertheless, in cell suspension or hairy root culture, the downstream processing is simpler. The first step required is exudation, i.e., to promote secretion of metabolites into the medium, of which could be achieved through elicitation, membrane permeabilisation (chemical and physical), and addition of cell wall-digesting enzyme [26].

It is then followed by extraction step, where generally for phytochemicals, organic solvents are used. Direct alcohol extraction might be feasible, however, for improved purity, the extraction can be started with a highly non-polar organic solvent (i.e., to remove fats and oils), followed by alcohol extraction (usually proved to be a good solvent), and finally with an additional liquid-liquid extraction (e.g., aqueous tartaric acid solution and ethyl acetate). Optimization of extraction condition: $\mathrm{pH}$, temperature, duration, solvent types, and proportion, the solid-to-liquid ratio should also be carried out. Selection of solvent should be made in regard to compounds' stability. One point to note, for food application (as in this $M$. pudica case), inherently toxic solvents like benzene, hexane, and chloroform should be avoided and replaced with cyclohexane, heptane, toluene, and methylene chloride [23]. The use of supercritical fluid extraction should also be considered to minimize the use of organic solvents and for improved extraction efficiency.

In addition, for further purification, which is crucial for compound characterization study, the purification scheme is similar to the microbial system (i.e., use of sequential chromatography, counter-current chromatography, and integrated method like aqueous two-phase system). Here, clarification step prior to primary recovery methods is crucial Filtration is preferred over centrifugation as it is normally single-use (minimum contamination risk) and is more scalable.

\section{Conclusion}

Notably, besides the technical challenges in the biotechnological production route, other hurdles include aseptic cultivation of the plant, Good Manufacturing Practice (GMP) compliance, and the need for plant viruses' removal.
Ironically, the concept of minimal processing or even the use of whole plants is tempting as it lowers cost of production and eases administrative hassle. However, there is also a concern on the resulting organoleptic properties of the food product, of which should be extensively examined. More specific studies on the antimicrobial efficacy on targeted food borne pathogens and interaction with the food component of the particular food product should also be studied. Furthermore, besides the phytochemicals, the potential of plant antimicrobial peptide (PAP) (if there is any in M. pudica) as biopreservative should also be looked into.

\section{References}

1. Elsser-Gravesen D, Elsser-Gravesen A (2014) Biopreservatives. Adv Biochem Eng Biotechnol 143: 29-49.

2. Tiwari BK, Valdramidis VP, $\mathrm{O}^{\prime}$ Donnell CP, Muthukumarappan $\mathrm{K}$ Bourke P et al. (2009) Application of natural antimicrobials or food preservation. J Agric Food Chem 57(14): 5987-6000.

3. Lucera A, Costa C, Conte A, Del Nobile MA (2012) Food applications of natural antimicrobial compounds. Front Microbiol 3: 287.

4. Bali V, Panesar PS, Bera MB, Kennedy JF (2016) Bacteriocins: recent trends and potential applications. Crit Rev Food Sci Nutr 56(5): 817834 .

5. Jamaluddin N, Stuckey DC, Ariff AB, Wong FWF (2017) Novel approaches to purifying bacteriocin: A review. Crit Rev Food Sci Nutr: $1-13$.

6. Volkov AG, Foster JC, Markin VS (2010) Signal transduction in Mimosa pudica: biologically closed electrical circuits. Plant Cell Environ 33(5): 816-827.

7. Muhammad G, Hussain MA, Jantan I, Bukhari SNA (2016) Mimosa pudica L., a high-value medicinal plant as a source of bioactives for pharmaceuticals. Compr Rev Food Sci Food Saf 15(2): 303-315.

8. Sharma MC, Sharma S (2010) Phytochemical and pharmacological screening of combined Mimosa pudica Linn and Tridax procumbens for in vitro antimicrobial activity. Int J Microbiol Res 1(3): 171-174.

9. Ahmad H, Sehgal S, Mishra A, Gupta R (2012) Mimosa pudica L. (Laajvanti): An overview. Pharmacogn Rev 6(12): 115-124.

10. Compean KL, Ynalvez RA (2014) Antimicrobial activity of plant secondary metabolites: a review. Res J Med Plant 8(5): 204-213.

11. Rajalakshmi K, Banu N (2016) Antimicrobial activity of natural chlorophyllin from endangered medicinal plant Mimosa pudica L. Int J Pharm Pharm Sci 8(4): 387-389.

12. Mohan G, Anand SP, Doss A (2011) Efficacy of aqueous and, ethanol extracts of Caesalpinia sappan L. and Mimosa pudica L. for their potential antimicrobial activity. South As J Biol Sci 1(2): 48-57.

13. Le Thoa NT, Cam Nam P, Minh Nhat D (2015) Antibacterial activities of the extracts of Mimosa pudica L. an In-vitro study. Int J Adv Sci Eng Info Tech 5(5): 358-361

14. Genest S, Kerr C, Shah A, Rahman MM, Saif-E-Naser GMM, et al. (2008) Comparative bioactivity studies on two Mimosa species. Bol Latinoam Caribe Plant Med Aromaticas 7(1): 38-43.

15. Panda D, Kumar Dash S, Kumar Dash G (2012) Antimicrobial potentia of crude extracts and isolates of roots of Mimosa Pudica Linn. collected from the locality of Mohuda Environ, Ganjam, Odisha. Int J Pharm Sci Res. 3(10): 3725-3734.

16. Cushnie TP, Cushnie B, Lamb AJ (2014) Alkaloids: an overview of their antibacterial, antibiotic-enhancing and antivirulence activities. Int Antimicrob Agents 44(5): 377-386. 
17. Kaur P, Kumar N, Shivananda TN, Kaur G (2011) Phytochemica screening and antimicrobial activity of the plant extracts of Mimosa pudica L. against selected microbes. J Med Plants Res. 5(22): 53565359.

18. Cushnie TP, Lamb AJ (2005) Antimicrobial activity of flavonoids. Int J Antimicrob Agents. 26: 343-356.

19. Arabski M, Węgierek-Ciuk A, Czerwonka G, Lankoff A, Kaca W (2012) Effects of saponins against clinical E. coli strains and eukaryotic cell line. J Biomed Biotechnol 286216.

20. Trombetta D, Castelli F, Sarpietro MG, Venuti V, Cristani M, et al. (2005) Mechanisms of antibacterial action of three monoterpenes. Antimicrob Agents Chemother 49(6): 2474-2478.

21. Shan B, Cai YZ, Brooks JD, Corke H (2007) Antibacterial properties and major bioactive components of cinnamon stick (Cinnamomum burmannii): activity against foodborne pathogenic bacteria. J Agric Food Chem 55(14): 5484-5490.
22.Janssen A, Scheffer J, Baerheim-Svendsen A (1986) Antimicrobial activity of essential oils: A 1976-1986 literature review on aspects of test methods. Planta Med 53(5): 395-398.

23. Georgiev MI, Weber J, Maciuk A (2009) Bioprocessing of plant cell cultures for mass production of targeted compounds. Appl Microbiol Biotechnol 83(5): 809-823.

24. Gecchele E, Schillberg S, Merlin M, Pezzotti M, Avesani L (2014) A downstream process allowing the efficient isolation of a recombinant amphiphilic protein from tobacco leaves. J Chromatogr B Analyt Technol Biomed Life Sci 960: 34-42.

25. Łojewska E, Kowalczyk T, Olejniczak S, Sakowicz T (2016) Extraction and purification methods in downstream processing of plant-based recombinant proteins. Protein Expr Purif 120: 110-117.

26. Cai Z, Kastell A, Knorr D, Smetanska I (2012) Exudation: an expanding technique for continuous production and release of secondary metabolites from plant cell suspension and hairy root cultures. Plant Cell Rep 31(3): 461-477.

\section{Your next submission with Juniper Publishers will reach you the below assets}

- Quality Editorial service

- Swift Peer Review

- Reprints availability

- E-prints Service

- Manuscript Podcast for convenient understanding

- Global attainment for your research

- Manuscript accessibility in different formats

( Pdf, E-pub, Full Text, Audio)

- Unceasing customer service

Track the below URL for one-step submission https://juniperpublishers.com/online-submission.php 